\title{
ENTRE O SAGRADO E A CAATINGA O OURO BRANCO SURGE SOB O OLHAR HUMANITÁRIO DE UM EMPREENDEDOR SOLIDÁRIO
}

Antonia Márcia Rodrigues Sousa ${ }^{1}$ Alexandre Oliveira Lima ${ }^{2}$

Fabiana Pinto De Almeida Bizarria ${ }^{2}$

Alcineide Aguiar Pimenta ${ }^{3}$

${ }^{1}$ Universidade Federal de Mato Grosso do Sul

${ }^{2}$ Universidade da Integração Internacional da Lusofonia Afro-Brasileira

${ }^{3}$ Faculdade Luciano Feijão 


\section{ENTRE O SAGRADO E A CAATINGA O OURO BRANCO SURGE SOB O OLHAR HUMANITÁRIO DE UM EMPREENDEDOR SOLIDÁRIO}

\section{RESUMO}

Este caso para ensino relata a trajetória de projeto social conhecido mundialmente como "Cabra Nossa de Cada Dia" em alusão ao pai nosso, onde se expressa o pão nosso de cada dia, que fala da vida por meio do leite que mata a fome do sertanejo. Criado pelo religioso empreendedor social Padre João Batista Frota no interior do Ceará para combater a fome e as mazelas provocadas pela seca que assolava o ano de 1993, provocando um alto índice de mortalidade infantil e de idosos. Para melhor compreensão da extensão social e do reconhecimento do projeto, buscou-se informações em revistas, artigos científicos, relato técnico, livros e entrevistas com o fundador do projeto, coordenador geral os coordenadores locais. O Caso tem viabilidade acadêmica para os cursos de graduação e pós-graduação lato sensu em Administração, Ciências Sociais, Sistema de Informação gerencial ou áreas afins, particularmente nas disciplinas de Gestão social, Empreendedorismo, Economia solidária, gestão de pequenos negócios. Afere-se a relevância para essas disciplinas por apresentar um consorciados de informações que perpassam desde os princípios norteadores que regem a arte de detectar oportunidades que sustentam o meio ambiente, a comunidade e a economia por sua capacidade de empreender, seja na perspectiva social ou econômica.

Palavras-Chave: Projeto Social. Cabra Nossa de Cada dia . Empreendedor Social.

\section{DO PRELÚDO NA CAATINGA AO APOGEU DO OURO BRANCO}

No ano de noventa e três

ao Nordeste a seca chegou

No solo de Sobral

A fome se alastrou

com miséria e privação

E o povo do campo clamou

Tão severa a seca foi que mudou a realidade

Da criança e do velho

Não contou a idade

Fosse moça ou senhora

Matou sem piedade

Parecia a seca de 15

Que castigou o Ceará

Um novo desafio

Para o povo "superá"

Agora era a hora
De unir forças e se "juntá"

Muito crítica a situação

Que o êxodo rural subiu

Sem alimento e sem higiene

A população sumiu

Até que o gestor público

Ao alarido do povo ouviu

Faltava um pouco de tudo

De comida a bebida

Até roupa e calçado

O básico pra vida

Veio até cesta e carro-pipa

Não deu conta, dura era a lida

E a peleja continuou

Porque nem só de pão se vive

A fé também alimenta 
E a religião sobrevive

No coração do caboclo

A fé com a religião convive

Mas um homem de visão

Muito além percebeu

Viu mais que a dor do povo

Novo caminho percorreu

Uniu a fé e a razão

No social empreendeu

Inspirado no Evangelho quis dar vida em abundância a todos da comunidade deu imensa importância buscou parceiros e amigos até fora das suas instâncias

Apesar das dificuldades Padre João Batista persistiu Criou projetos e parcerias Ao assistencialismo resistiu E o "Cabra Nossa de Cada Dia" Como solução surgiu

Porém, dinheiro não havia

Pra o projeto iniciar

E pelos olhos da fé

Padre João pôde enxergar

E com coragem convocou

Os amigos do além-mar

Bem distante, da Alemanha Veio o socorro financeiro 50 cabras boas de leite Formaram o rebanho primeiro Rotary, UVA, EMBRAPA, Seagri

Tornaram-se parceiros

Não acabaram os desafios

A descrença ainda existia

No coração de uns poucos

Mas a fome persistia

O projeto, então, vingou
Era o início do fim da carestia

Na pequena São Joaquim

Foi então edificado

$\mathrm{O}$ primeiro aprisco

com 150 animais doados

A comunidade viu

Os primeiros resultados

De acordo com critérios

Assim, cada morador

Recebeu uma cabra prenhe

Pra ficar ao seu dispor

Com o leite disponível

$\mathrm{O}$ caboclo virou produtor

Milagre e multiplicação

No sertão aconteceram

A partir da reprodução

Novas cabras nasceram

E mudanças sociais

e econômicas trouxeram

Vieram muitos ajustes

Para melhor adaptação

Das diferentes comunidades

Exigindo mais coordenação

Com acompanhamento

$\mathrm{E}$ até prospecção

O projeto só cresceu

Até Associação já existia

O ouro branco salvou vidas

Mas a fome persistia

O projeto, então, vingou

Era o início do fim da carestia

E foram muitas as famílias

Pelo Projeto atendidas

Com o passar dos anos

Mais de mil crianças assistidas

$\mathrm{O}$ reconhecimento veio

Prêmios por ajudar vidas 
O primeiro em 2008

Um prêmio nacional

O Atitude Cidadã

E em 2011 novo aval

agora da Presidência

mais avanço social

Com o dever cumprido

E a missão repleta

Padre João Batista

Segue nova meta

Deixa a solidariedade

Mais um ciclo se completa

Mas surgiu um dilema,

Pra se autossustentar

A associação precisou

Estratégias implantar

E da imagem física

Do fundador se desligar

Assim, a comunidade

Em busca de independência

Procurou mecanismos

Pôs-se em diligência

Pra encontrar autonomia

Com ajuda da ciência

Mais uma vez com o apoio

Das instituições de fomento

A Associação avançou

Difundiu conhecimento

Ofereceu cursos técnicos

E se viveu ali novo momento

As lideranças cresceram

E se reuniram pra avaliar

As ações desenvolvidas

E puderam constatar

Que muitas barreiras

O Projeto conseguiu superar
De 1998 a 2004 “mió” irrigação

Pro plantio de pastagem

E pro cuidado das hortas

E tinha um vantagem

Até uma farmácia viva

que recriava a paisagem

Já de 2004 a 2008

Veio mais renovação

Chegaram novas cabras

Com alto índice de lactação

Boas pro chão sertanejo

De excelente fertilização

E não parou por aí

As famílias tiveram ganhos

Com a criação de peixes

A formação de rebanhos

Mais cursos técnicos

Viu-se crescer mais o sonho

Também a Secretaria

de Saúde de Sobral

Reconheceu as ações

do Projeto social

na erradicação da fome

e no apoio assistencial

Somado a isso tudo

A orientação empreendedora

E a ajuda do SEBRAE

Tornaram mais promissora

Com pequenos negócios

A realidade vindoura

Mudou tanto a comunidade

Até no que era intangível

Cresceu o respeito parental

Tudo subiu de nível

A autoestima feminina

Agora mais aprazível 
Mas foi assim como o Padre

Um dia chegou a relatar

O Cabra Nosso de Cada Dia

Veio se concretizar

Por que muitos trouxeram

"Pães e peixes" para multiplicar

Sem o envolvimento

De todos da comunidade

A vida das famílias

Possivelmente e na verdade

Teria levado um fim triste

Mas o empenho fez nova realidade

$\mathrm{E}$ as alianças cresceram

Pra levar o bem aos corações

Expertise da Embrapa

Da SEAGRI doações

Apoio técnico da UVA

Melhorando as ações
Além dessas ainda teve

Ajuda até da Alemanha

Do Rotary Club Forchheim

E daqui pra não perder a sanha

Prefeitura, DNOCS, DETRAN

E empresas fizeram campanha

Assim o Padre João Batista

Com um simples ato solidário

Salvou inúmeras famílias

Deu ao Sertão outro cenário

Com o empreendedorismo social

Bendito seja nosso vigário!

Que Deus lhe dê em dobro

Por cada gesto realizado

E o Cabra Nosso de Cada Dia

Seja mais ainda abençoado

E o Bem seja a cada dia

Mais e mais disseminado. dilemas:

Diante das evidências sociais expostas, o grupo gestor vive envolto aos seguintes

Desvincular a imagem do Pe. João Batista Frota, mentor e fundador do projeto, pode comprometer a permanência dos parceiros na associação e a continuidade do projeto?

Quais estratégias autossustentáveis que a associação deve implementar para desvincular sua imagem social da imagem física do seu fundador?

Quais mecanismos os gestores devem utilizar para tornar o projeto autossustentável, tornando os coordenadores locais autônomos, contando ainda com o apoio dos parceiros? 


\section{NOTAS DE ENSINO}

\section{FONTE DE DADOS}

Os dados foram coletados por meio de suporte teórico em artigos científicos, periódicos, relato técnico, livros e entrevistas com o fundador do projeto, coordenador geral, e os coordenadores locais.

\section{OBJETIVOS EDUCACIONAIS}

Com base na narrativa do caso, sugere-se uma análise e discussão com abordagem nas seguintes temáticas e direcionamentos.

1. Apresentar os principais aspectos comportamentais que define o fundador como um empreendedor social

2. Descrever os principais processos norteadores da gestão social do projeto e propor soluções viáveis para os questionamentos apresentados nos dilemas propostos.

3. Identificar, em ordem cronológica, a implantação de ações no projeto que configuram perfil de empreendedorismo social.

4. Mapear as características sociais do projeto que o torna empreendimento autossustentável

5. Apontar os elementos geradores de valor social do projeto.

\section{TÓPICOS PEDAGÓGICOS}

\section{APLICAÇÃO RECOMENDADA}

Propõe-se que o caso seja utilizado em distintas áreas, mas especificamente, apresentase uma proposta inerente a um celeiro de discussões para os alunos dos cursos de graduação e pós-graduação lato sensu em Administração, Ciências Sociais, Sistema de Informação gerencial ou áreas afins, particularmente nas disciplinas de Administração geral, Empreendedorismo, Economia solidária, gestão de pequenos negócios e antropologia.

Afere-se a relevância para essas disciplinas por apresentar um consorciado de informações que perpassam desde os princípios norteadores que regem a arte de detectar oportunidades que sustentam o meio ambiente, a comunidade e a economia por sua capacidade de empreender, seja na perspectiva social ou econômica.

Ainda apresenta um cenário prospectivo para discutir a gestão no contexto econômico de gerir e tornar sustentável e no direcionamento social orientado pelos princípios da ética e da solidariedade, observando a existência do homem e seu agrupamento a partir dos valores, costumes e compartilhamento do que pensa, sente e faz. 


\section{DINÂMICA E AGENDA PARA DISCUSSÃO DO CASO}

A operacionalização dessa etapa, deve ocorrer por meio de um planejamento antecipado da leitura do caso e das sugestões apresentadas para suporte teórico. Orienta que o caso seja trabalhado ao longo de uma aula de 60 minutos de duração. Para isso, o quadro 1 sugere um planejamento sumarizado para viabilizar as discussões.

Quadro 1. Planejamento das discussões

\begin{tabular}{|c|l|}
\hline Dduração & \multicolumn{1}{|c|}{ Atividades } \\
\hline 10 min & $\begin{array}{l}\text { Apresentação geral do caso com seus pressupostos teóricos e a formação dos } \\
\text { grupos para as discussões. }\end{array}$ \\
\hline 10 min & $\begin{array}{l}\text { Contextualização do caso com a exposição dos objetivos propostos. } \\
\text { Apresentação dos questionamentos com as respectivas proposições teóricas. }\end{array}$ \\
\hline 15 min & Apresentação, discussão e alinhamento teórico com as respostas dos grupos. \\
\hline 15 min & $\begin{array}{l}\text { Argumentação dos grupos para solução dos dilemas propostos e sua } \\
\text { integração com a literatura. }\end{array}$ \\
\hline 10 min & Considerações finais. \\
\hline
\end{tabular}

Fonte: Elaborado pelos autores (2018)

\section{QUESTÕES PARA DISCUSSÃO E ANÁLISE TEÓRICA DO CASO}

Nesta etapa, o professor deve dividir a turma em até cinco membros, podendo variar conforme o tamanho. Orienta-se, com base no planejamento sugerido no quadro 1, que o professor apresente os dilemas, objetivos, em seguida, associe os questionamentos ao posicionamento teórico propostos dos autores indicados no texto.

I - Baseado nos direcionamentos teóricos dos autores indicados no texto, identifique as principais características de empreendedorismo Social apresentadas no projeto Cabra Nossa de Cada Dia.

McClelland (1971) fundamenta a procedência do empreendedor, apontando algumas características do comportamento empreendedor: busca de oportunidades e iniciativa, persistência, comprometimento, exigência de qualidade e eficiência, correr riscos calculados, estabelecimento de metas, busca de informações, planejamento e monitoramento sistemático, persuasão e rede de contatos, independência e autoconfiança.

O empreendedor tem como características a iniciativa, autonomia, autoconfiança, necessidade de realização, perseverança e tenacidade para vencer obstáculos, capacidade de se dedicar ao trabalho e concentrar esforços para alcançar resultados, comprometimento: crê no que faz (DOLABELA, 1999).

O indivíduo que se denomina empreendedor, traz para si singularidades atitudinais que provém do espirito transformador, que acredita na possibilidade de mudança através de suas ideias e seus ideais.

As características dos empreendedores sociais estão conectadas aos problemas sociais sob o prisma de melhoraria nas comunidades em que trabalham, propagando políticas sociais
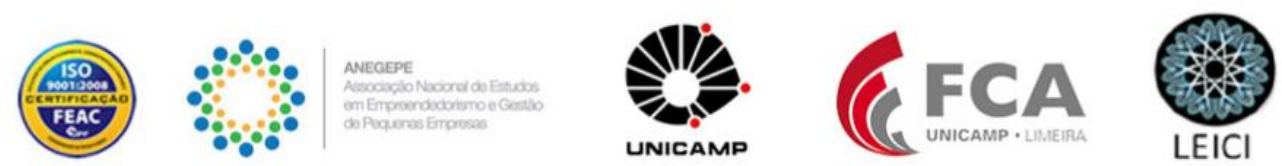
de apoio aos suprimidos socialmente, bem como apresentando propostas que consolidem e possibilitem transformações socioculturais e econômicas nas localidades que possuem parceria (PEREIRA, CORDEIRO E BATISTA, 2012; BARROS, ÁVILA; MADRUGA, 2013; RIBAS, 2011; SOUSA, PAIVA JR., 2012; MODICA, 2009; GAIGER, 2008).

A coletividade é uma característica latente do empreendedor social, pois esse está sempre buscando encontrar solução para os problemas sociais e o desprovimento da comunidade, prima pela solidariedade e reciprocidade, tem cuidado com o meio ambiente e promoção da dignidade. Então ao contrário do empreendedor empresarial que tem como parâmetro a lucratividade, o empreendedorismo social tem como relevância o resultado gerado por suas ações na sociedade, especialmente no cuidado das causas dos menos favorecidos pela sociedade.

Gaiger (2007) ressalta que essa relação positiva entre os aspectos solidários, de gestão coletiva e de cooperação no trabalho, e aspectos empreendedores, de organização dos fatores produtivos e de sua gestão adequada ao enfrentamento dos obstáculos e à realização das metas econômicas, constituiu o objeto de uma análise pormenorizada dos dados gerais do primeiro Mapeamento Nacional da Economia Solidária no Brasil.

Para Roper e Cheney (2005) o que difere os empreendedores sociais dos chamados empreendedores "regulares" é o comprometimento gerado pela motivação social independente de interesses por recompensas financeiras. Sendo assim, são pessoas desprovidas de interesses próprios e que tendem a sensibilizar-se com a causa do outro, tendo como recompensa, apenas as mudanças positivas geradas na vida desses indivíduos.

Segundo Oliveira (2006), os empreendedores sociais possuem características comuns como ideias inovadoras, à percepção de oportunidades e a posição de assumir riscos. A motivação de seus esforços é gerada, antes de tudo, pela visão do impacto do seu trabalho na melhoria na vida das pessoas. É destacado também, o sentido prático desses indivíduos, colocados como acostumados a resolver problemas concretos. São pessoas altruístas, que são movidas pelo espirito motivador da transformação em prol do bem comum.

\section{II - Tomando como base as proposições teóricas sobre empreendedorismo social, identifique as ações implantadas no projeto que se associam a referida literatura?}

O crescimento do empreendedorismo social tem contribuído para reduzir a desigualdade na distribuição de renda em distintas comunidades do nordeste por meio da implantação de projetos sociais que se apoiam nas potencialidades locais para desenvolver suas regiões. $\mathrm{Na}$ visão de Dess (2001) o empreendedor do século XX e XXI independente do segmento de atuação, deve trazer em sua essência, o desejo de mudança e de fomento a transformação social por meio integração de ações que mobilizem a comunidade.

Para Yunus, (2008) uma iniciativa inovadora independe da sua grandeza, se vai contribuir para a melhoria econômica ou não econômica da vida de pessoas ou comunidades, pode ser descrito como empreendedorismo social.

Tal referência, comunga com a definição de Zahra, Gedajlovic, Neubaum e Shulman, $(2009$, p.5) , ao afirmarem que o empreendedorismo social acontece por meio de "atividades e processos realizados para descobrir, definir e explorar as oportunidades a fim de aumentar a riqueza social através da criação de novos empreendimentos ou pela gestão das organizações existentes de maneira inovadora".

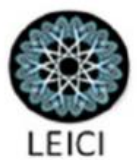


O empreendedorismo social está centrado nos processos de criação, manutenção, distribuição e disseminação de valor social ou ambiental de forma inovadora por meio de operações corporativas, ocorridas em empreendimentos sociais, instituições sem fins lucrativos, instituições públicas ou privadas" (GRANADOS et al., 2011, p. 199).

Segundo Dess (2001) os empreendedores sociais atuam como indutores de mudanças ao adotarem uma missão para criar e manter valor social; pelo reconhecimento e a busca incessante de novas oportunidades com intuito de servir; pelo empenho continuo em prol da inovação, adaptação e aprendizagem e por sua ação ousadia na utilização de recursos limitados e no fazer social sem olhar a quem.

Em complemento, Melo Neto; Fróes, (2002, p. 81) advogam que os empreendedores sociais tem como foco buscar soluções para os problemas sociais mediante necessidades da comunidade, medindo o sucesso através do desempenho, impacto social das atuações, atitudes e comportamentos, ou seja, o número de pessoas no programa ou projeto de empreendedorismo social.

"Empreendedores Sociais são definidos como indivíduos ou organizações privadas que tomam a iniciativa para identificar e resolver importantes problemas sociais nas suas comunidades. Organizações e indivíduos que desenvolvem novos programas, serviços, e soluções para problemas específicos e aquelas que resolvem as necessidades de populações especiais" KOROSEC ; BERMAN,2006, p. 448-449).

Para o alinhamento entre os questionamentos propostos no caso e os construtos teóricos sobre empreendedorismo social como fenômeno nacional e internacional, sugere-se o entendimento do empreendedorismo social como empoderamento das comunidades na solução dos seus problemas sociais(Melo Neto; Fróes, 2002); Atividade inovadora que cria valor social e tem suas estratégias de mercado baseadas nos valores e benefícios sociais(Austin, Stevenson, e Wei-Skillern, 2006;Perrini 2011; Light 2005); Catalizador de mudanças sociais positivas que impactam nas atuais e nas futuras gerações (Kerlin 2006; Bacq e Janssen, 2011); permite a geração de valor social por meio de empreendimentos economicamente sustentáveis com a missão de oferecer benefício social aos menos favorecidos (Dacin et al. 2010); Valor partilhado (PORTER; KRAMER, 2011).

Partindo de uma visão prática, Osborne (2011, p.15), relaciona o empreendedorismo social ao provérbio chinês: " Dá-lhe um peixe, e alimentá-lo-às por um dia; ensina-o a pescar, e alimentá-lo-às para a vida". Nessa ótica, o empreendedorismo social cria possibilidades para que as pessoas consigam maximizar as suas condições sociais por meio das oportunidades criadas pelo empreender social, especialmente, aproveitando as potencialidades locais. o empreendedorismo social aspira à criação das condições que permitam que as pessoas consigam ultrapassar os seus próprios problemas sociais (CLERCQ ; HONIG, 2011).

\section{IV - Considerando os aspectos teóricos descritos no texto a seguir, aponte as ações implantadas no projeto Cabra Nossa de Cada Dia que apresentam conotações autossustentáveis.}

Para Boaventura de Sousa Santos (2004), vive-se um tempo paradoxal, em que de um lado se tem instrumentos suficientes para que haja igualdade, solidariedade, liberdade e paz, porém ao olhar para outra direção, logo percebe-se o quanto vive-se de fato, distantes de livrarse das algemas do assistencialismo.

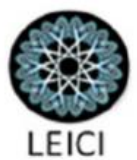


Nesse sentido, é salutar que os coordenadores locais compreendam que o escopo de atuação do projeto Cabra Nossa de Cada Dia, não é meramente um solucionador das questões sociais, mas sim, um mecanismo de empoderamento para a comunidade na solução dos seus problemas sociais vigentes e de possíveis vindouros.

É nessa proposta que Tenório (2008) defende um gerenciamento mais participativo, dialógico, no qual o processo decisório deve ser exercido por meio de diferentes sujeitos conscientes do seu papel como agente social emancipado.

Esse compartilhamento de papéis no gerenciamento das ações oriundas do empreendedorismo social fortalece a compreensão do grupo em relação ao comprometimento e estimula o indivíduo como ator social com direito a expressão sem coação.

Melo Neto; Fróes, (2002) advogam que a comunidade ao executar ações de empreendedorismo social deve ser autogestora dos seus projetos sociais, sem a interferência de terceiros. Portanto, todo trabalho deve ser realizado com o intuito de que seus principais beneficiados sejam a própria comunidade.

Assim, nos reportamos a Yunus (2010) ao afirmar que o propósito do negócio social é a criação de valor social, por meio da comercialização de produtos ou serviços, nos quais "o princípio de maximização dos lucros é substituído pelo princípio do benefício social.

Segue na contramão da empresa tradicional em que a sua principal finalidade é o lucro como recompensa pelos valores investidos. Os negócios sociais "visam alcançar objetivos sociais, além disso, o lucro deve ser integralmente investido na organização"(YUNUS, 2010, p. 37).

Carrion (2007) defende que a gestão social tem como centro a "boa" governança local, na qual, além de existir espaço para a participação democrática e deliberativa dos cidadãos, deve criar condições para esta participação, considerando o conflito de interesses como parte integrante do projeto democrático.

Na percepção de Tenório; Saraiva (2006, p.128) o contexto da gestão social implica "numa hegemonia em que as ações possuem caráter intersubjetivo. Ou seja, onde os interessados na decisão, na ação de interesse público, são participantes do processo decisório".

Portanto, entende-se que o projeto Cabra Nossa de Cada Dia, como um negócio social que está inserido no contexto da economia solidária, em que Singer (2004), defende que esse tipo de economia é formada principalmente, por empreendimento autogestionários que atuam em distintos segmentos com uma visão estratégica, inovadora, senso de oportunidade, eficiência de gestão e efetividade de resultados, elementos preponderantes ao empreendedorismo social (DRUCKER, 1987).

No contexto geral, a gestão social é aquela orientada para o social enquanto finalidade, e pelo social enquanto processo, sendo orientada pelos princípios da ética, da solidariedade e seguindo um norteamento contemporâneo é permeada por uma visão estratégica inovadora e emancipativa nas relações de caráter produtivo (TENÓRIO; SARAVIA, 2006). O gestor social "é um gestor do simbólico e do valorativo, especialmente quando se trata de culturas locais e da construção de identidades" (FISCHER, 2002, p.28). 
III - Com base nos estudos de Portocarrero e Delgado (2010) e nos demais direcionamentos teóricos apresentados, identifique os principais elementos geradores de valor social do Projeto Cabra Nossa de Cada Dia.

A criação de valor social e econômico proveniente das ações de empreendedorismo social devem ser tratada de forma congruentes e sinérgicas, onde a criação de valor em cada uma deve ter sua grandeza, que consorciadas otimizam o valor total criado (ZHANG; SWANSON, 2013).

Kerlin, (2006) advoga que no cenário norte-americano, a empresa com conotação social é aquela que inclui qualquer ação empreendedora de mercado que gera impacto social por meio de sensibilização, produção e comercialização de algum produto, ou conscientização dos envolvidos em prol de uma causa social traga como mudança, a transformação da qualidade de vida dos beneficiados.

Márquez, Reficco e Berger (2009), defendem que as múltiplas faces de um negócio social não deve ficar restrita apenas a sua autossustentabilidade e rentabilidade, é fundamental que a empresa promova uma associação de benefícios sociais e ambientais que agregue valor econômico e social na vida das pessoas transformando o seu bem estar diário.

Observa-se a existência de crescente negócios com conotações sociais, entretanto, Yunus (2007) defende apenas a existência de dois tipos de negócios sociais, estando o primeiro relacionado as empresas que tem como propósito prover algum tipo de beneficio social com fins a redução da pobreza, sustentabilidade global, justiça social e ao tratamento de saúde das pessoas menos favorecidas, sem nenhum interesse de maximização de lucro por parte do investidor. E o segundo tem relação direta com a maximização de lucro, mas a propriedade pertence as pessoas que estão a margem da pobreza. Assim, os dividendos e o crescimento financeiro serão investidos para reduzir a pobreza, e em beneficos sociais para melhorar a qualidade de vida das pessoas e o desenvolvimento economico e social da comunidade.

Para Comini (2016) dentre os distintos componentes como capital fisíco, social, humano, outra forma de classificar a geração de valor em negócios sociais é a divisão entre os aspectos tangíveis(acesso a bens, serviços e geração de renda) e intangíveis (resgate da cidadania e desenvolvimento do capital social) como forma de encontrar elementos que possam mensurar os seus benefícios na minimização da vulnerabilidade das comunidades envolvidas.

Em um estudo desenvolvido por Portocarrero e Delgado (2010) em 33 negócios sociais na região ibero-americana, alguns achados apontaram a necessidade de ampliação em relação a elementos tangíveis que fortaleçam a criação de valor das iniciativas destinadas a população em estado de pobreza ou com renda a baixo das condições de subsistência.

Ainda segundo Portocarrero e Delgado (2010) alguns indicadores apresentam elementos que enfatizam os impactos e a geração de valor social fomentado pelos negocios sociais, conforme descrito na figua 1. Elementos norteadores de Geração de Valor Social 


\begin{tabular}{|c|c|}
\hline Aumento de renda & Acesso a bens e serviços \\
\hline $\begin{array}{l}\text { Matérias-primas produzidas, } \\
\text { principalmente em área rurais, para } \\
\text { as empresas, particularmente } \\
\text { produtos agrícolas ou relacionados à } \\
\text { agricultura. } \\
\text { - Organização de produtos e } \\
\text { associação ou incorporação a cadeias } \\
\text { produtivas. } \\
\text { - } \text { Aumento de produtividade advindo } \\
\text { de treinamento e assessoria técnica. } \\
\text { - } \text { Eliminação de intermediário } \\
\text { Economias em compras frequentes } \\
\text { Certificação para produtos } \\
\text { diferenciados. }\end{array}$ & $\begin{array}{l}\text { - } \quad \text { Redução de preços } \\
\text { - } \quad \text { Pagamento fragmentado de bens e } \\
\text { - } \quad \text { Presiços e sistemas pré-pagos. } \\
\text { áreas pobres em áreas rurais e } \\
\text { - } \quad \text { Eliminação de barreiras a educação } \\
\text { - Investimentos privados em } \\
\text { equipamentos, infraestrutura e redes } \\
\text { de distribuição. }\end{array}$ \\
\hline $\begin{array}{l}\text { Promoção de cidadania } \\
\text { - } \quad \text { Reconhecimento e exercício de } \\
\text { direitos básicos (vida, trabalho, } \\
\text { saúde, educação, etc) } \\
\text { - } \quad \text { Defesa de interesses públicos } \\
\text { - } \quad \text { Maior visibilidade e dignidade para } \\
\text { setores de baixa renda e grupos } \\
\text { excluídos. } \\
\text { - Intermediação de oportunidades de } \\
\text { trabalho para pessoas com } \\
\text { deficiência, grupos excluídos ou } \\
\text { indivíduos não qualificados. } \\
\text { Validação da identidade de } \\
\text { indivíduos não registrados. } \\
\text { Acesso físico ao mercado para } \\
\text { vender a produção do setor de baixa } \\
\text { renda. } \\
\text { Consciência ambiental } \\
\text { Promoção de bons hábitos de } \\
\text { higiene, ordem e consumo racional. }\end{array}$ & $\begin{array}{l}\text { Desenvolvimento de capital social } \\
\text { - } \quad \text { Construção de redes, } \\
\text { relacionamentos locais e } \\
\text { fortalecimento de capacidades. } \\
\text { - Construção de um sentimento de } \\
\text { pertencimento a uma comunidade. } \\
\text { - Construção de rede social, confiança, } \\
\text { reciprocidade e desenvolvimento de } \\
\text { cooperação. } \\
\text { Maior disponibilidade de recursos } \\
\text { próprios e de terceiros por meio de } \\
\text { contatos e interações. } \\
\text { Capacitação do setor de baixa renda } \\
\text { para agilizar e expressar as } \\
\text { demandas. } \\
\text { - } \text { Melhora da autoestima } \\
\text { - } \text { Ligsociação de interesses individuais. } \\
\text { administrações, empresas, novos } \\
\text { mercados ou clientes locais. }\end{array}$ \\
\hline
\end{tabular}

Fonte: Adaptado de Portocarrero e Delgado (2010)

Os indicadores propostos na figura 1 , estão intrinsecamente voltados para mitigar os problemas advindos da vulnerabilidade social que acomete a população de baixa renda, expressando a criação de uma identidade social e de um equilíbrio entre o valor social e econômico dessas comunidades. 


\section{Notas Explicativas:}

Parcerias:

A realização do projeto Cabra Nossa De Cada Dia é pautado nos direcionamentos do provérbio "fazer o bem sem olhar a quem". Com essa máxima, o Padre João Batista Frota, ao longo dos anos, foi formando grandes parcerias que se tornaram responsáveis pela grandeza social do projeto nos mais diversos quesitos técnicos, gerenciais e financeiros. A EMBRAPA Caprinos Empresa Brasileira de Pesquisa Agropecuária, com sua expertise oportuniza desde o início a capacitação técnica nos mais diversos estágios desde o processo de inseminação artificial ao melhoramento genético do rebanho. A universidade Estadual Vale do Acaraú-UVA, por meio do curso de Zootecnia, no apoio técnico à produção correta do leite com fins à fabricação de queijo e doce de leite de cabra. A Secretaria de Agricultura do Estado do Ceará-SEAGRI participou da doação de mais 100 cabras mestiças que foram distribuídas para as 17 comunidades que atualmente são atendida. A Prefeitura Municipal de Sobral, por meio da Secretaria de Agricultura e Pecuária apoia a manutenção de hortas, sítios, apicultura e piscicultura. O Rotary Club Forchheim da Alemanha ajudou financeiramente na construção abrigos para os animais, cacimbas e plantação de capim em treze comunidades. O Serviço de Apoio às Pequenas e Médias Empresas -SEBRAE apoia a capacitação dos jovens com metodologias voltadas para o apoio ao desenvolvimento local. O Departamento Nacional de Obras contra as Secas - DNOCS com a doação de 60 hectares de terra para pastagens dos animais e construção de sítios em duas comunidades. A Pastoral da Criança da Paróquia do Patrocínio na orientação alimentícia das crianças e nos problemas de saúde em geral. $\mathrm{O}$ departamento Nacional de Transito - DETRAN apoia com a doação de caprinos e ovinos apreendidos, as empresas privadas Big pneus, Sobral Gráfica, Augusto Azevedo Engenharia, Moageira Serra Grande e Instituto de Estudos e Pesquisas do Vale do Acaraú-IVA apoiam com recursos financeiros, apoio logístico, alimento para os animais transporte e materiais de manutenção do projeto

\section{REFERÊNCIAS}

AUSTIN, J.; STEVENSON, H. ; WEI-SKILLERN, J. Social and commercial entrepreneurship: Same, different, or both? Entrepreneurship Theory and Practice, 30 (1), 1-22, 2006.

BARROS, I. C. F.; ÁVILA, L.V.;MADRUGA, L.R.R.G. Empreendedorismo: Soluções inovadoras para questões sociais. Desenvolvimento em Questão. Ed. Unijuí. Ano 11, n. 23, 2013.

BACQ, S.; JANSSEN, F. The multiple faces of social entrepreneurship: A review of definitional issues based on geographical and thematic criteria.Entrepreneurship \& Regional Development: An International Journal, 23 (56), 373-403, 2011.

CARRION, R. da S. M. Gestão social: especificidades e práticas em discussão. In: SILVA, J. G. et al. (Org.). Tecnologias de gestão: por uma abordagem multidisciplinar. Vitória: EDUFES, v. 2, p. 108-124, 2007.

CLERCQ, D.; HONIG, B. Entrepreneurship as an integrating mechanism for disadvantaged persons. Entrepreneurship \& Regional Development: An International Journal, 23 (5-6), 353372, 2011.

COMINI, G.M. Negócios sociais e inovação social:um retrato de experiências brasileiras. Tese (Livre Docência) - Universidade de São Paulo-USP, São Paulo, 2016.

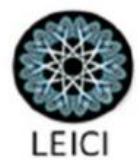


DACIN, P.; DACIN, M.; MATEAR, M. Social entrepreneurship: Why we don't need a new theory and how we move forward from here. The Academy of Management Perspectives, 24 (3), 37-57, 2010.

DEES, J. The meaning of social entrepreneurship. Stanford University: Center for Social Innovation. 2001. Acessado em 22 de fevereiro de 2018, em http://www.caseatduke.org/documents/dees sedef.pdf

DOLABELA, F. Oficina do empreendedor. São Paulo: Editora de Cultura, 1999.

DRUCKER, P. F. Inovação e espírito empreendedor. São Paulo: Pioneira , 1987

FISCHER, T. M D. Poderes locais, desenvolvimento e gestão - uma introdução a uma agenda. In FISCHER, T. M D. (Org.). Gestão do desenvolvimento e poderes locais: marcos teóricos e avaliação. Salvador: Casa da Qualidade, p.12-32, 2002.

GAIGER, L.I. Otra Economía - A dimensão empreendedora da economia solidária: Notas para um debate necessário. V. II - $\mathrm{N}^{\circ} 3$ - 2 $2^{\circ}$ semestre/ 2008 - ISSN 1851-4715 Www.riless.org/otraeconomia (Acessado em: 16 de fev. 2018).

GRANADOS, M. L. et al. Social enterprise and social entrepreneurship research and theory: a bibliometric analysis from 1991 to 2010. Social Enterprise Journal, v. 7, n. 3, p. 198- 218, 2011.

KERLIN, J. A comparative analysis of the global emergence of social enterprise. Voluntas: International Journal of Voluntary and Nonprofit Organizations, 21 (2), 162-179, 2010. KERLIN, J. A. Social enterprise in the United States and Europe: Understanding and learning from the differences. Voluntas, 17(3), 247-263, 2006.

KOROSEC,; BERMAN, E. Municipal support for social entrepreneurship. Public Administration Review, 66 (3), 448-462, 2006.

LIGHT, P. Searching for social entrepreneurs: Who they might be, where they might be found, what they do. In annual meetings of the Association for Research on Nonprofit and Voluntary Associations, 2005. Acessado em 26 de fevereiro 2018, em http://wagner.nyu.edu/performance/files/Searching\%20for\%20Social\%20Entr

epreneurship.pdf

MARQUEZ, P.; REFICCO, E. e BERGER, G. Negócios inclusivos en América Latina. Harvard Business Review. P.. 28-38. Maio de 2009.

MELO NETO, F. P. de; FRÓES, C. Empreendedorismo social: a transição para a sociedade sustentável. Rio de Janeiro: Qualitymark, 2002.

MCCLELLAND, D.C. Entrepreneurship and achievement motivation: approaches to the science of sócio-economic development. In: LEYGEL, P (org.).Paris:UNESCO, 1971

MODICA, R. As Redes Europeia e Global dos Geoparques (EGN e GGN): proteção do patrimônio geológico, oportunidade de desenvolvimento local e colaboração entre territórios. Geol. USP, Publ. espec., oct. 2009, vol.5, p.17-26. ISSN 1676-7829.

PEREIRA, G.D.F.;CORDEIRO, A.T.; SILVA, M.A.P.;BATISTA,M.M. Empreendedorismo regional: um olhar sobre a identidade cultural em narrativas locais - XXXVI encontro ANPAD/ Rio de Janeiro, 2012.

OLIVEIRA, E. M. Empreendedorismo Social: Da Teoria à Prática, Do Sonho à Realidade. Rio de Janeiro: Qualitymark, 2008.

OSBORNE, G. You Can't Fish Without a River. Tennessee's Business, 20 (1), 15-16, 2011.
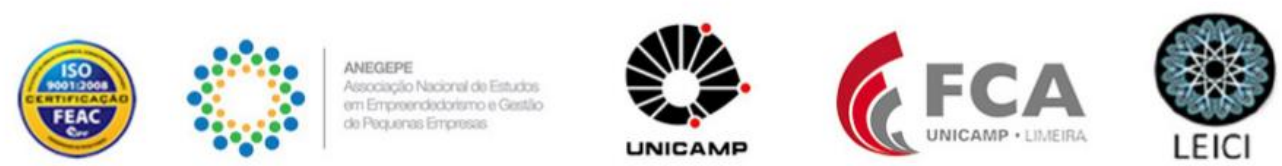
PERRINI, F.; VURRO, C.;COSTANZO, L. A process-based view of social entrepreneurship: From opportunity identification to scaling-up social change in the case of San Patrignano. Entrepreneurship \& Regional Development: An International Journal, 22 (6), 515-534, 2010. PORTER, M. E. ; KRAMER M. R. "The Big Idea: Creating Shared Value, Rethinking Capitalism", Harvard Business Review. January-February 2011. v 89 Issue 1/2, pp.62-77.

PORTOCARRERO, F; DELGADO, S. Negocios Inclusivos y generación de valor social in: In: MÁRQUEZ,P.; REFICCO, E.; BERGER,G. Negocios inclusivos - Iniciativas de mercado con los pobres de Iberoamérica. Bogotá, Colômbia: Amaral Editores / BID, 2010.

RIBAS, R.L. A motivação empreendedora e as teorias clássicas da motivação. Caderno de Administração - PUC. Vol.1, .n.1, 2011.

ROPER, J.; CHENEY, G. Leadership, learning and human resource management: the meaning of social entrepreneurship today. Corporate Governance, Malden, v. 5, n. 3, p. 95- 104, 2005.

SANTOS, B. de S. Produzir para viver: os caminhos da produção não capitalista. Porto: Afrontamento, 11-19, 2004.

SINGER, P. Desenvolvimento : significado e estratégia. Texto para discussão. Brasília : MTE/SENAES, maio de 2004.

SOUSA, J. L. de., PAIVA JR, F. G. Empreendedorismo no Setor Público: A dinâmica da Fundação Joaquim Nabuco. Recife: Fundação Joaquim Nabuco, Editora Massangana - 2012.

TENÓRIO, Fernando Guilherme; SARAVIA, Henrique J. Escorços sobre gestão pública e Gestão Social. In: MARTINS, Paulo Emílio Matos; PIERANTI, Octavio Penna. Estado e gestão pública: visões do Brasil contemporâneo. 2. ed. Rio de Janeiro: FGV, 2006, 340p.

TENÓRIO, Fernando Guilherme. (Re)visitando o conceito de Gestão Social. In: SILVA JR, Jeová Torres; MÂISH, Rogério Teixeira; CANÇADO, Airton Cardoso; SCHOMMER, Paula Chies. Gestão Social: Práticas em debate, teorias em construção. Fortaleza: Imprensa Universitária, 2008.

YUNUS, M. Social business entrepreneurs are the solution. In A. Nicholls (Ed.) Social Entrepreneurship: new models of sustainable social change (3944). New York: Oxford University Press, 2008.

YUNUS, M. Social Business what it is and what it is not. In: Creating a World Without Poverty, New York, Public Affairs, p. 21-40, 2007.

YUNUS, Muhammad. Um mundo sem pobreza, a empresa social e o futuro do capitalismo. $1^{\text {a }}$ ed. $3^{\mathrm{a}}$ impressão. São Paulo: Ática, 2010.

VIEIRA, R. T. Cabra nossa de cada dia. Salvador: Solisluna Designd e Editora, 2009.

ZAHRA, S.; RAWHOUSER, H.; BHAWE, N.;NEUBAUM, D.; HAYTON, J. Globalization of social entrepreneurship opportunities. Strategic Entrepreneurship Journal, 2 (2), 117-131, 2008.

ZHANG, D.D. SEANSON, L.A.Social Entrepreneurship in Nonprofit Organizations: An Empirical Investigation of the Synergy Between Social and Business Objectives. Journal of Nonprofit \& Public Sector Marketing, Volume 25, 2013 - Issue 1. 
ANEXO: Fotos do Projeto

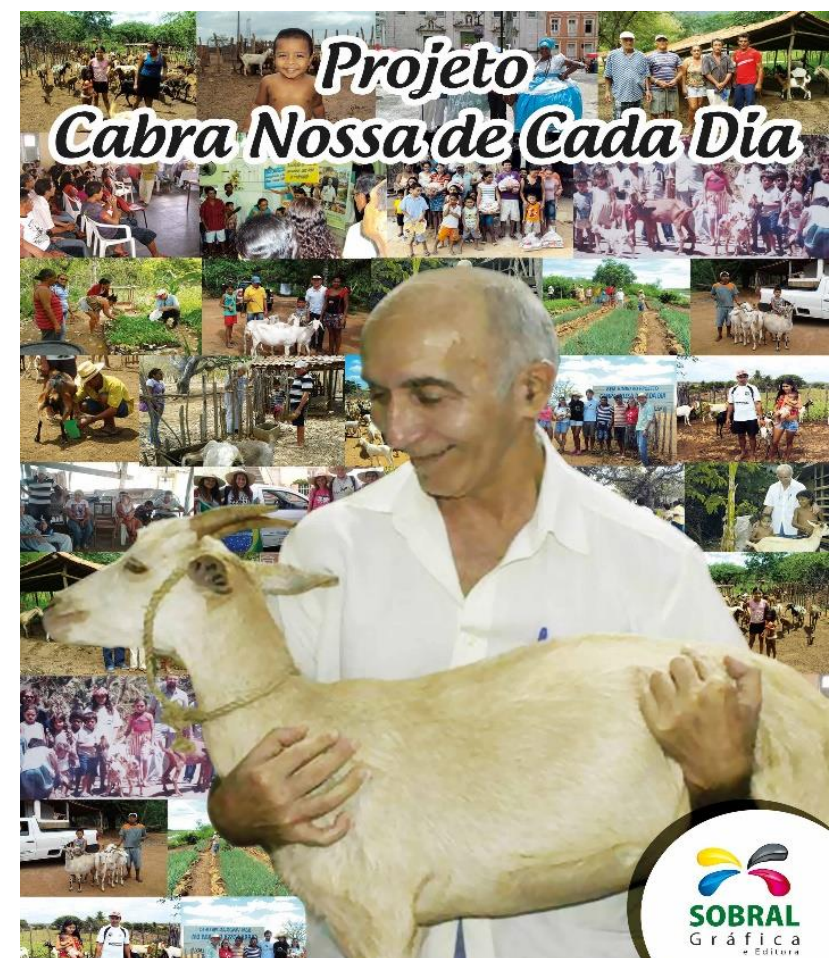

Padre João Batista Frota - Fundador do Projeto

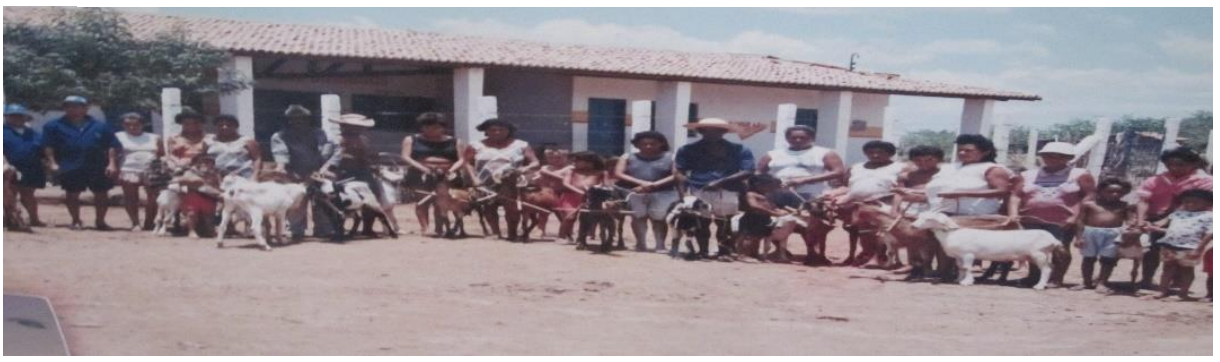

Comunidade São Domingo - Início do projeto em 1993

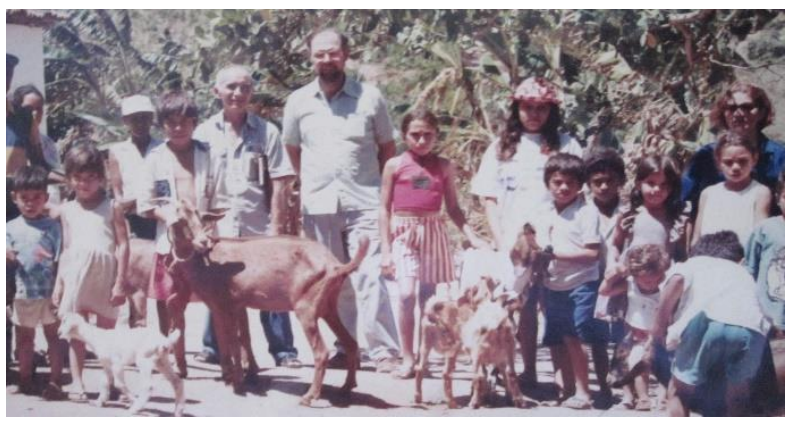

Visita de um dos amigos da Alemanha que doaram as primeira cabras

Fotos cedidas pelo Coordenador do Projeto Jorge Luís 